\title{
Profissionais como produtores de redes: tramas e conexões no cuidado em saúde
}

\section{Professionals as network producers: compositions and connections in health care}

\author{
Viviane Santalucia Maximino \\ Universidade Federal de São Paulo. Santos, SP, Brasil. \\ E-mail: vivimax9ळgmail.com
}

\section{Flavia Liberman}

Universidade Federal de São Paulo. Santos, SP, Brasil. E-mail: toflavia.liberman®gmail.com

\section{Maria Fernanda Frutuoso}

Universidade Federal de São Paulo, Santos, SP, Brasil. E-mail: fernanda.frutuoso®unifesp.br

\section{Rosilda Mendes}

Universidade Federal de São Paulo. Santos, SP, Brasil. E-mail: rosilda.mendesळunifesp.br

\section{Correspondência}

Viviane Santalucia Maximino

Rua Silva Jardim, 136, Vila Mathias. Santos, SP, Brasil. CEP II060-00।.

\section{Resumo}

Este artigo apresenta resultados parciais de uma pesquisa-intervenção realizada em unidades básicas de saúde e procura problematizar processos de cuidado de saúde em rede. Acompanhando percursos cotidianos de usuários, selecionados por equipes dos serviços, indaga como e quando as redes ficam mais potentes e produzem saúde ou, ao contrário, se enfraquecem. Verificam-se redes de atenção amplas, operacionalizadas de diversas maneiras e compostas por múltiplos vetores e elementos formais e informais, visíveis e invisíveis, objetivos e subjetivos que contribuem para facilitar ou dificultar a construção de pontos de articulação entre serviços, pessoas e recursos para o cuidado. Com o recorte dos profissionais como produtores de rede, discute-se as tensões entre sistemas de ordenação e hierarquização e a perspectiva de uma rede de caráter rizomático, os fluxos de encaminhamento e os movimentos que os diferentes atores realizam na produção da rede de cuidado. Trazendo para o centro os usuários, seus direitos e os limites e as potencialidades de seus lugares sociais, pôde-se perceber fragilidades na produção do cuidado, na composição das redes e na promoção da saúde. Verifica-se também que recursos e conexões são cotidianamente reinventados no encontro entre instituições e sujeitos, que se afetam mutuamente e podem apoiar as práticas de cuidado em rede.

Palavras-chave: Cuidado de Saúde em Rede; Atenção Básica; Pesquisa-Intervenção; Profissional de Saúde; Sistema Único de Saúde. 


\section{Abstract}

This article presents partial results of an intervention research performed in basic health units and seeks to problematize health care networks. Following daily paths of users, selected teams from services, it was asked how and when networks become more powerful and produce health or, on the contrary, when they weaken themselves. Health care networks are broad and operationalized in different ways. They articulate multiple vectors consisting of formal and informal, visible and invisible, objective and subjective elements that contribute to facilitate or to hinder the construction of points of articulation between services, people and resources to health care. Considering professionals as network producers, we discuss the tensions between ordering and hierarchical systems and the perspective of a rhizomatic network, the routing flows and the movements that the different actors involved perform to produce the care network. Bringing to the center the users, their rights and the limits and potentialities of their social places, we could see weaknesses in the production of care, in the composition of the networks and in the promotion of health. Also, it turns out that resources and connections are reinvented in the daily encounter between institutions and subjects, which affect each other and can support the practices of network care.

Keywords: Network Health Care; Basic Care; Intervention Research; Health Professionals; Brazilian National Health System.

\section{Introdução}

Este artigo apresenta resultados da pesquisa-intervenção Atenção básica e a produção do cuidado em rede no município de Santos, que teve como cenário de estudo onze unidades do Sistema Único de Saúde (SUS) local, realizada de 2014 a 2016. Um dos objetivos da pesquisa foi identificar, acompanhar e problematizar processos de cuidado de saúde em rede, nos quais estão envolvidos usuários e trabalhadores da atenção básica. Indagamos se o percurso cotidiano dos usuários, suas relações e ações em rede nos territórios apontam ou não possibilidades que potencializam, enriquecem e transformam a vida, produzindo e promovendo saúde.

No âmbito do cuidado em saúde, as redes podem ser consideradas decisivas, seja pela organização do sistema de saúde, que implica ações coordenadas de diversos serviços e setores, seja pela constatação empírica de que o cotidiano e a manutenção da vida parecem apoiados em conexões diversas: de familiares, vizinhança, trabalho, amizade etc. Sendo assim, o conhecimento de quais seriam as redes de sustentação e cuidado que incluem, mas não se reduzem, a rede da atenção primária, secundária e terciária, interessa a todo o sistema de saúde e contribui para o fortalecimento de princípios fundantes do SUS como a integralidade e a equidade (Mendes, 2011).

Tomando particularmente as diretrizes do Ministério da Saúde, a implementação das Redes de Atenção à Saúde (RAS) possibilitaria a integralidade do cuidado a partir da organização de ações e serviços de saúde em seus diferentes níveis. Para fortalecer a gestão do cuidado em espaços regionais, a partir da construção permanente e ações nos territórios e equipamentos, as RAS colocam a atenção básica como um lócus importante de ordenação e coordenação do cuidado e de porta de entrada do sistema (Brasil, 2014), aspectos que serão problematizados neste artigo.

As redes investigadas neste estudo são muito mais amplas do que aquelas indicadas nas RAS, pois articulam múltiplos e diferentes vetores, que comportam elementos formais e informais, visíveis e invisíveis, objetivos e subjetivos presentes nos protocolos, leis e diretrizes institucionais, nas práticas profissionais, nos saberes dos pesquisadores 
da universidade e dos serviços e nas diferentes concepções sobre cuidado, redes, intervenção, formas de pesquisar, entre outros.

A produção da saúde se faz por meio de complexas redes de relações. Não são poucos os autores que têm-se debruçado em investigações acerca do conceito de rede na área de saúde e não se pretende aqui esgotar suas diferentes perspectivas, mas reafirmar aquilo que elas nos trazem como possibilidade de potencializar os inúmeros encontros de diversas naturezas (Kalichman; Ayres, 2016; Kiss; Schraiber; Oliveira, 2007; Malta et al., 2014; Mendes, 2011; Prates; Garcia; Moreno, 2013; Torres; Belisario; Melo, 2015).

Cabe, no entanto, dar destaque a algumas outras proposições. Ao realizar uma análise sistêmica da vida, de entrelaçamento e interdependências entre todos os fenômenos, Capra (1996) a faz entendendo rede como o padrão básico de organização de todo e qualquer sistema vivente, biológico e social. Ou seja, se rede é um padrão comum a todo tipo de vida, onde quer que deparemos com vida, constatamos redes. Não é sem razão que ele considera a vida tecida em "redes dentro de redes". Arranjar o sistema hierarquicamente, como uma pirâmide é uma "projeção humana [...] Na natureza não há 'acima' ou 'abaixo' e não há hierarquias. Há somente redes aninhadas dentro de outras redes" (Capra, 1996, p. 45).

Para Kastrup (2003), o único elemento constitutivo da rede é o nó, por suas conexões, por seus pontos de convergência e de bifurcação. Aponta as redes ferroviárias, marítimas, neurais, imunológicas e de informática que não são definidas por seus limites externos, mas por suas conexões internas, ou seja, não podem ser caracterizadas como uma totalidade fechada, dotada de contornos definidos, e sim um todo aberto, sempre capaz de crescer a partir de seus nós, por todos os lados e direções. A rede destaca-se assim, por ser vazada, composta de linhas e não de formas espaciais. 0 primado das linhas sobre as formas evoca ainda o conceito de rizoma, criado por Deleuze e Guattari, que explicitam alguns princípios que balizam sua constituição. A rede é uma corporificação do rizoma, um campo visível onde ocorre o que chamamos de agenciamentos. Esses agenciamentos são compostos por vários elementos, inclusive heterogêneos, “como o rizoma, a rede articula elementos heterogêneos como saberes e coisas, inteligências e interesses" (Kastrup, 2003, p. 57).

Ressaltamos ainda a noção de redes vivas destacadas como o modo de produção das conexões existenciais de indivíduos e coletivos, em diferentes contextos grupais, exercendo uma significativa influência na produção do cuidado (Merhy et al., 2014).

Neste artigo, considera-se rede formal, aquela da qual fazem parte as estruturas e os procedimentos instituídos para a função cuidadora. Merhy et al. (2014) consideram essa rede institucionalizada do sistema de saúde como analógica que pode ser disparadora, mas será atravessada por inúmeras outras redes, de tipos não analógicos, como as hipertextuais e existenciais, sem que tenhamos controle absoluto sobre elas. Denominamos esses outros formatos de redes informais, compostas por vários "sinais" e que, apesar de não previamente designadas para isso, também participam dos processos de saúde-doença-cuidado.

As redes que emergiram nesta pesquisa, no acompanhamento das diferentes situações de cuidado, desenharam linhas e conexões entre usuários, profissionais, familiares, equipamentos, territórios, entre outras. 0 material produzido revela redes de atenção que são construídas de maneira bastante diversas e que muitos são os fatores que contribuem para potencializá-las e/ou enfraquecê-las. Este artigo busca analisar, a partir da centralidade do usuário, como os profissionais de saúde tecem e produzem a rede de cuidados. Indagamos como e quando as redes ficam mais potentes e produzem vida e saúde, ou, ao contrário, apenas reforçam nossas ofertas instituídas e enfraquecem as tramas e conexões do cuidado em saúde.

\section{Caminhos da pesquisa}

Este estudo adotou a pesquisa-intervenção, que pressupõe a participação daqueles que de alguma forma estão envolvidos no ato de pesquisar. Seguindo as guias do método cartográfico, o percurso da pesquisa foi produzido com os sujeitos. A opção pela pesquisa-intervenção e pela cartografia parte da orientação de que o trabalho do pesquisador não se faz de modo prescritivo, mas é construído em 
processo. Todo o saber prévio é colocado em questão a partir do momento em que se busca construir uma atenção de pesquisador que não está pronta de antemão (Kastrup, 2007; Passos; Barros, 2009). Pesquisadores da universidade, dos serviços de saúde e os sujeitos selecionados construíram coletivamente uma maneira de mapear a experiência.

A pesquisa foi elaborada em etapas que aconteceram concomitantemente ou como desdobramento umas das outras. Na primeira etapa foram realizadas oficinas com as equipes de unidades básicas de saúde, nas quais subgrupos de pesquisadores, da universidade e dos serviços, exploraram casos e/ ou situações marcantes que trouxessem o tema das redes, indicando um deles para aprofundamento. Em outra etapa, de acordo com a singularidade de cada contexto, os pesquisadores realizaram aproximações e ações com os sujeitos selecionados a fim de conhecer as redes formais e informais acionadas e como os diversos atores contribuíram ou não para a efetivação das redes de cuidado.

Em todo o percurso foram utilizadas diferentes linguagens como dispositivo nas oficinas e encontros com usuários, como desenhos, fotos, diagramas, mapas etc. O registro das experiências foi sistematizado em Diários de Pesquisa (DP), redigidos coletivamente pelos subgrupos de pesquisadores. Trata-se, portanto, de uma ação metodológica que comporta a heterogeneidade em relação aos ritmos, formações, habilidades dos pesquisadores, dando visibilidade aos acontecimentos e experiências vividas nos diferentes campos (Pezzato; L'Abbate, 2011).

O processo de análise ocorreu por meio da leitura do conjunto de diários e da busca de palavras-chave: "redes", "articulação" e "relação", que permitiram um agrupamento inicial nos seguintes temas: usuário como produtor de rede, profissionais como produtores de redes e ferramentas produtoras de rede. Para auxiliar a análise foi produzido um quadro em que os pesquisadores registraram trechos, comentários e referências bibliográficas, relacionados aos agrupamentos. Procurou-se estabelecer uma relação interrogativa com o material de modo a ampliar a compreensão dos sentidos presentes nos discursos abrindo novas problematizações à investigação, ou seja, buscou-se "pensar com" o material produzido.
Neste artigo focalizaremos as redes produzidas pelos profissionais de saúde, os fatores que dificultam e/ou enfraquecem sua produção, bem como o que as potencializam. Delineamos dois vetores, intimamente articulados, que explicitam a organização dessas redes. Um deles segue um ordenamento instituído e diz respeito à estrutura piramidal, verticalizada, que pretende organizar o sistema de saúde, e outro, que resulta da tensão permanente com os acontecimentos que "escapam" dessa lógica e que buscam, de diferentes modos, traçar outros trajetos que respondam às necessidades, limites e potências dos próprios usuários e dos trabalhadores que gravitam em cada situação. Nesse segundo caso trazemos o que chamamos de uma rede rizoma para expressar a produção da rede de cuidados.

\section{Organização piramidal: possibilidades e tensões}

Os profissionais de saúde são atores importantes de uma rede institucional cuja organização de trabalho está pautada nos problemas de saúde mais relevantes que, na maioria das vezes, correspondem às áreas temáticas prioritárias indicadas pelo Ministério da Saúde e Secretarias Municipais de Saúde (Silva, 2011; Silva et al., 2011). Pudemos observar que estes produzem redes a partir de seu modo de pensar e operar as ações em saúde, construídas por macro e micropolíticas, ou seja, pela organização formal do sistema de saúde que determina uma estrutura institucional e também pelos conceitos, formas de cuidado em saúde e pelos lugares sociais ocupados pelos sujeitos. Os trechos dos DP ilustram suas concepções, modos de pensar/operar, revelando obstáculos e invenções do cotidiano do trabalho em saúde.

Diversos fatores podem potencializar ou dificultar o funcionamento em rede. Em primeiro lugar, a estrutura piramidal da organização dos fluxos de usuários pelo sistema parece criar mais barreiras e fragmentação do que conexão e circulação, termos que definem rede no sentido mais amplo aqui utilizado. A atenção básica vem sendo indicada como porta de entrada do sistema de saúde que deve encaminhar o usuário a um serviço especializado, quando necessário. A complexa relação entre atenção 
básica e especializada foi um tema recorrente nesta pesquisa, confirmando as análises já apontadas na literatura (Campos et al., 2011; Serra; Rodrigues, 2010; Silva, 2011; Venâncio; Rosa; Bersusa, 2016).

Encontramos nas narrativas dos profissionais reclamações e julgamentos dessa ordenação que se processa por meio de encaminhamentos, sendo que para preservar suas identidades citamos siglas DPU acompanhadas de um número, referente a cada uma das unidades mencionadas. Esse percurso protocolar pode "amarrar" as estratégias de cuidado, pois, ao encaminhar o usuário, o profissional pode se desresponsabilizar do cuidado e contribuir para a fragmentação das ações de saúde.

A técnica diz que a especialidade não manda a resposta para a UBS, isto é, não há retorno. $\varepsilon$ diz que a UBS também não tem interesse em saber o que aconteceu e que a equipe tem que ter esse interesse (DPU6).

A produção de rede refere-se a conexões e disputas de poder, sobretudo nas relações hierarquizadas entre os profissionais e as diferentes ações e serviços, que incidem diretamente nessa produção: "Uma das ACS fala que muitas vezes a relação com o especialista está permeada por uma "guerra de vaidades' e essa relação é problemática” (DPU4).

A atenção básica ainda é vista como simples, de menor complexidade, por isso é desvalorizada. Nas especialidades estaria o saber e aqueles profissionais mais habilitados para fazerem diagnósticos e tratamentos. Essa concepção espraia-se entre os profissionais e usuários e cria uma cultura competitiva que dificulta a cooperação e a produção de redes, pois desqualifica a capacidade do outro em dar continuidade ou mesmo "compreender" o cuidado que está sendo produzido.

A inclusão da dimensão subjetiva nas práticas de saúde é um dos desafios mais importantes colocados pelo SUS, obrigando-nos a atentar para o que se produz na relação entre os sujeitos, às várias formas de grupalidade e aos processos de subjetivação em sua relação com o protagonismo, a autonomia e a corresponsabilidade entre trabalhadores, gestores e usuários dos equipamentos de saúde. A heterogeneidade das necessidades, articulada ao direito de todos preconizados pelo SUS, coloca outro desafio: criar unidade na diferença. A ideia de unidade mesmo que não homogênea contrasta com a fragmentação e a baixa comunicabilidade frequentemente encontradas no funcionamento dos serviços segmentados em suas áreas, setores e programas (Passos; Carvalho, 2015).

A enfermeira diz que é preciso detalhar mais os relatos, mas também precisa de uma maior conscientização do pessoal de fora (do ambulatório) (DPU4).

No trecho anterior fica evidente o distanciamento entre as equipes das especialidades e da atenção básica. A expressão "de fora" indica um modo de funcionamento contrário à concepção de rede rizomática, composta por pontos e articulações, sem dentro e nem fora. Essa situação dificulta e até mesmo impede o trabalho cooperativo.

Nesse caso, diante de uma solicitação de esclarecimento diagnóstico feita ao especialista, há uma desconfiança de que a Unidade Saúde da Família (USF) não tenha feito seu trabalho. A equipe da USF alegou que "se este profissional conhecesse a rotina de seus atendimentos, saberia que estes exames iniciais já haviam sido feitos, sem sucesso" (DPU4). A enfermeira que fez o comentário acima afirmou também "que não havia estudado nada sobre a ESF [equipe saúde na família] na graduação e tudo o que sabia, tinha aprendido na prática" (DPU4). A equipe diz que pouco sabe sobre os atendimentos e o fluxo dos serviços especializados, que não há reuniões entre chefias da atenção básica e os gestores dos outros níveis de atenção, nem entre equipes de diversos serviços que estão em um mesmo território e atendem a mesma população.

Azevedo et al. (2013) indicam que o trabalho em saúde é permeado por relações humanas que envolvem vínculo, escuta, comunicação e responsabilização com o cuidado, ressaltando que solidariedade, trabalho, cooperação e cogestão são constantemente evocados nos textos de referência para os aparatos legais, mas carecem de uma discussão prática de como isto se daria.

Dessa maneira, como é possível "azeitar" a rede? Diante das diferentes complexidades das situações vivenciadas pelos profissionais, quais estratégias 
operariam como conectivos da rede? Nesse sentido, podemos nos apoiar no conceito de transversalidade indicado por Guattari (apud Passos; Carvalho, 2015) que, ao colocar lado a lado os diferentes, embaralha a verticalização, que hierarquiza a comunicação entre estes e também a horizontalidade, que faz que a comunicação entre os iguais seja corporativa. Podemos perguntar se a estrutura organizacional do SUS facilita ou inibe que se efetivem seus princípios norteadores, principalmente os de participação e territorialização.

Os profissionais citam o caso de "uma paciente queixosa que está sempre na unidade" (DPU4) e os encaminhamentos parecem, algumas vezes, ter a função de aliviar a equipe, mesmo que momentaneamente, de alguma situação difícil. A ausência de diálogo entre os profissionais e da participação do usuário na gestão do cuidado podem ter contribuído para a manutenção da verticalização na relação especialista - equipe saúde da família - usuário.

Inúmeros usuários são atendidos por dois ou mais serviços, de acordo com a necessidade, o que exigiria articulação entre estes:

A enfermeira informa que atualmente há 16 gestantes da área de abrangência da equipe. Três delas fazem pré-natal na casa da gestante (alto risco), $e$ três são adolescentes (menores de 18 anos). A médica diz que não se desliga dessas gestantes de risco, pois elas retornam quando o bebê nasce (DPU4).

É interessante notar que a médica tenha feito essa referência, pois, sendo a atenção básica o lócus principal de acompanhamento das famílias, é esperado que continue a acompanhar a puérpera e seu bebê. No entanto, muitas vezes o usuário vincula-se ao especialista e não volta à unidade básica ou ainda mantém os dois vínculos não necessariamente articulados.

Vimos que essa dupla vinculação possibilita que o usuário maneje as datas de consulta e a aquisição de medicamentos, garantindo dois ou mais locais que possam atender às suas necessidades. Essa situação onera o sistema com um excesso de consultas ou com faltas, o usuário algumas vezes segue condutas contraditórias simultaneamente, entre outras questões. As dificuldades em conseguir consultas, exames e medicação, a ausência de trabalho conjunto entre os serviços, que poderia facilitar o acompanhamento do usuário, entre outras, são hipóteses possíveis para essa situação. Pode-se considerar ainda a posição do usuário e suas possibilidades de ter voz e ser mais ativo nesse processo.

Outra usuária acompanhada na pesquisa devido ao episódio relativo à morte da filha, como desfecho de uma discussão familiar, também mobiliza múltiplos serviços com outras estratégias de conexão entre eles. Após a prisão pela morte da filha, a usuária teve um diagnóstico psiquiátrico, sendo internada e acompanhada pela Unidade Básica de Saúde, pelo Núcleo de Apoio Psicossocial (NAPS) e pelo Centro de Referência da Assistência Social (CRAS), demonstrando uma rede que se compõe com recursos intersetoriais.

Para essa e outras situações de cuidado, uma função citada é a do técnico de referência (TR), encontrada formalmente nos serviços de saúde mental e assistência social. Outra estratégia citada são os Projetos Terapêuticos Singulares (PTS). Profissionais e projetos singulares podem tanto facilitar como obstruir a construção da rede.

Em nossos acertos para a articulação da rede na qual N. transita, inicialmente uma ACS ficou com a tarefa de manter o contato com o NAPS. Porém, nas nossas conversas, esta sinalizou que estava difícil para ela, pois esteve no NAPS e não encontrou a assistente social de referência. Foi dizendo coisas interessantes sobre o PTS produzido à família de $N$., bem como as descontinuidades após a saída de cena da TR do CRAS (DPU2).

Nesse trecho percebe-se que os projetos de intervenção estão diretamente ligados ao TR, o que pode ser positivo, favorecendo o cuidado singular, pautado no vínculo e na responsabilização. Este, ao se conectar com outros profissionais e serviços a partir daquilo que o caso pede, produz diferentes agenciamentos, levando à construção de uma rede rizomática. Isso exige mobilidade, flexibilidade em relação ao seu local e equipe de trabalho, reconhecimento da importância dessa função, possibilidades concretas de estabelecer comunicação, atitude atenta e disponível para acompanhar os processos, geralmente de alta complexidade. Esses profissionais 
têm espaço para compartilhar suas percepções e dúvidas sobre os casos, para pensar junto? O número de usuários sob sua responsabilidade e o tempo que se tem para dedicar a eles é compatível com suas reais condições de trabalho?

No caso citado, a impossibilidade de encontrar o TR dificultou a articulação entre os serviços. Outro aspecto encontrado na pesquisa indica que, ao assumirem esse papel, podem também represar informações dificultando que o caso seja de responsabilidade da equipe, ou ainda causar sobrecarga para os próprios profissionais de referência. As diretrizes para os serviços de saúde destacam a importância das reuniões de equipe para discussões de caso, que nem sempre ocorrem, contribuindo ou não para que a informação seja socializada.

Os prontuários não são eletrônicos e não podem ser acessados nos diversos pontos da rede, o que dificulta a troca de informações e seguimento dos casos. As relações entre os serviços são realizadas prioritariamente por meio de formulários, encaminhamentos, geralmente sucintos e insuficientes em relação às necessidades de comunicação dos profissionais:

O parecer do especialista, apresentado no formulário gerou um burburinho entre os profissionais, sobretudo na médica que demonstrou certo desânimo com a dificuldade em fazer um diagnóstico mais detalhado da usuária (DPU4).

Nota-se que a equipe parece não estabelecer outro tipo de contato com o especialista, seja para encaminhar um caso, ou para esclarecer uma resposta e, na impossibilidade de avançar, os profissionais sentem-se desanimados, impotentes.

Verifica-se excesso de burocratização e modos instituídos de funcionar, o que pode contribuir para a desvitalização dos profissionais que não arriscam modos criativos e cooperativos de proceder em relação aos casos. Por isso, caberia indagar: há receios em "inventar" maneiras não preconizadas, além dos protocolos já estabelecidos? Poderia a criação de outros procedimentos necessários trazer mais engajamento dos profissionais?

Encontramos, no entanto, situações em que foi possível flexibilizar o cuidado em saúde a partir da realidade e das necessidades dos usuários, escapando da lógica instituída:

A médica que aceitou realizar a consulta da segunda criança mesmo não estando agendada, a enfermeira e a agente que, ao perceberem e discutirem a necessidade do atendimento, criaram a possibilidade da consulta acontecer (DPU2).

No primeiro momento, essas atitudes parecem menores, contudo dão visibilidade a outra forma de pensar e realizar o trabalho, que também está presente nas equipes. Contrariamente ao que poderia ser pensado, o rompimento dos protocolos e fluxos de atendimento pode favorecer o trabalho e a articulação entre usuários e profissionais. O paradoxo é que estes deveriam facilitar a efetivação do cuidado.

Se não fosse o contato íntimo com a munícipe não haveria cuidado; Exige-se uma quebra de protocolos para haver cuidado; existe a rede, mas "não está rolando" (DPU4).

A partir desse trecho cabe questionar como e por quem são elaborados os diversos protocolos, o quanto expressam a realidade dos serviços e suas necessidades, e qual é o espaço que os profissionais e usuários têm ou não para serem protagonistas do cuidado. Os protocolos são referências e garantia de bom atendimento? Servem para quê ou para quem? A serviço de que se usam os protocolos? Há flexibilidade para adequar as estratégias às necessidades e desejos das equipes e usuários? O que oferece mais possibilidade para "escapar" dos protocolos e não usá-los de modo enrijecido e burocrático?

Podemos dizer que, por um lado, o uso dos protocolos pode acontecer sempre do mesmo modo, como uma ação definida a priori e que, portanto, não abre espaço para encontros possíveis, por outro, os protocolos podem se configurar como dispositivos rizomáticos, ou seja, mais um elemento que pode agenciar o cuidado em saúde, por vezes inusitado.

Outra problemática encontrada refere-se às políticas intersetoriais às vezes contraditórias que se chocam e se misturam com as concepções dos profissionais gerando conflitos e pouca resolutividade. Cada serviço ou setor segue regulações 
próprias e, por vezes, não há comunicação entre eles para o estabelecimento de fluxos que tenham o usuário como foco. Em um dos casos viu-se que a política de afastamento do trabalho nas situações de problemas de saúde e a conduta de uma médica da ESF, que acompanha os pacientes de forma longitudinal, foram conflitantes, uma vez que os peritos nem sempre aprovam as licenças solicitadas pelos médicos generalistas da atenção básica. Além disso, encontramos polêmicas corporativas e discriminatórias entre os profissionais, que também afetam os usuários:

Teve muitas dificuldades para afastar-se pelo INSS, pois o médico perito não aceitou o atestado da médica cubana que a assistia alegando que a mesma "não era médica". S. avaliou essa atitude do perito como absurda e afirma que a médica cubana que a atendia era muito competente. Só conseguiu a licença quando outra médica da USF assinou o atestado (DPU4).

O trecho aponta ruídos na articulação entre os serviços, com prejuízo não só para o usuário, mas também para os profissionais. Não aceitar um documento de um colega denota neste caso falta de confiança, discriminação, ou uma posição contrária a uma política governamental, o Programa Mais Médicos, expressa em uma atitude que deveria ser técnica. Neste caso específico parece não haver legislação que ampare o colega estrangeiro fazendo valer suas ações profissionais. O sistema todo é onerado, pois o usuário teve que voltar à unidade e solicitar o atestado novamente.

Por outro lado, outro trecho, referente ao programa de planejamento familiar, realizado pela ESF em conjunto com o Instituto da Mulher (serviço especializado) parece não apresentar problemas nos encaminhamentos. No entanto, as mulheres podem não receber as respostas que gostariam, o que pode indicar que nem sempre os objetivos institucionais estão em função das necessidades dos usuários.

A pesquisadora questiona como funcionam as atividades de planejamento familiar na unidade. A. responde que elas ocorrem uma vez por mês $e$ que há um encaminhamento para o Instituto da
Mulher. "Lá, todos os métodos contraceptivos disponiveis são apresentados”. Diz também que parte das mulheres está mesmo em busca da cirurgia de laqueadura, mas a lista de espera data de 2013. Existe um protocolo, uma série de requisitos para haver o encaminhamento (DPU4).

Aparentemente esse trecho revela uma insuficiência do sistema na oferta de procedimentos. Entretanto, ao aprofundarmos o caso vemos que se revela também uma legislação que atua como mecanismo de tutela ao exigir, por exemplo, que os cônjuges autorizem os procedimentos de esterilização "ela já tem nove filhos mas quando foi pedir a laqueadura, soube que precisava da autorização do companheiro, que não aceitou" (DPU4).

A maneira como os usuários são vistos e tratados depende de diversos aspectos, por exemplo, dos problemas mais relevantes de saúde, a partir do monitoramento de indicadores como o aumento da taxa de mortalidade infantil no município:

Na USF é para a gente estender o tapete vermelho para a gestante, mas na hora em que elas chegam na maternidade eles estendem é um tapete escorregadio para elas! (DPU4).

As equipes da atenção básica relatam que quando há um óbito materno ou infantil, elas são responsabilizadas, quando na verdade há muitos outros fatores em jogo, por exemplo, a atenção no momento do parto, além das condições de vida da população. Nos últimos anos, medidas assistenciais e sanitárias tiveram impacto positivo sobre a mortalidade infantil, no entanto, determinantes relacionados à exclusão social das famílias (pobreza extrema, desemprego, violência e uso de drogas), bem como ausência de rede de apoio social colocam o problema para além do setor saúde (Vanderlei; Navarrete, 2013).

Nesse sentido, uma dimensão da fragilidade do cuidado em rede parece estar relacionada à fragmentação em setores: educação, assistência social, saúde, trabalho etc., que dificulta a ação dos profissionais nas questões da vida dos usuários, que não podem ser compartimentalizadas. A intersetorialidade entendida como ideia-força que pode produzir sinergia e favorecer a integralidade foi 
relatada como desafio para o cuidado sendo vinculada a iniciativas dos profissionais.

É lindo cuidar de um indivíduo de forma integral, mas na prática é difícil. A dificuldade começa com a pequena quantidade de profissionais e a complexidade das situações, na prática não flui. Têm diferenças entre os profissionais, "aquele que consegue, faz; mas sozinho não se faz nada”. Hoje os profissionais estão mais abertos (DPU2).

A construção de redes deve ser ativa e haver, tanto quanto possível, esforço para estabelecimento de relações que favoreçam as possibilidades de diálogo e o trabalho em parceria. No entanto, os profissionais parecem se posicionar de maneira ambígua a respeito de sua responsabilidade nessa construção: ora dependente de um profissional, "aquele que consegue, faz”, ora de maneira mais reflexiva, indicando que a pequena quantidade de profissionais, os casos complexos e os diferentes regimes institucionais incidem diretamente sobre as possibilidades, ou não, de articulação da rede e de produção de cuidado. Nesse sentido, caberia arguir: Como envolver os profissionais? Como abrir espaços para discutir as parcerias em sua complexidade e criar estratégias institucionais, superando a pessoalidade das ações?

\section{A construção da rede de cuidado: uma possivel rede rizoma?}

Dar visibilidade às estratégias que os profissionais inventam para enfrentar o desafio do estabelecimento das conexões das redes na efetivação de uma política pública de saúde que aponte para a produção de vida não é tarefa fácil. No entanto percebem-se desvios, ou pequenos gestos, iniciativas, que se configuraram como produção de redes rizomáticas, criando movimentos e conexões inusitadas que produziram potência, ou minimamente, deram ensejo a outros modos de funcionamento nas relações entre pessoas, serviços e território.

Diante das dificuldades de construção de redes de cuidado, podemos considerar as redes que se constroem entre as equipes de uma mesma unidade como apoios importantes encontrados ou criados pelos profissionais: A enfermeira diz que há o grupo de gestantes, que reúne as gestantes da área de abrangência da USF e não somente desta equipe (DPU4).

Esse trecho demonstra haver um arranjo interno para a realização de um grupo envolvendo usuárias das várias equipes ao invés de cada equipe fazer sozinha. Há relatos de equipes que constroem "uma rede de apoio interno", possibilitando aprendizado aos trabalhadores e questionamentos sobre o fazer profissional, criando mecanismos de cuidado e vínculo com os usuários.

$V$. já exigiu muito dela, relata que a fez questionar se estava sendo uma boa profissional e que cogitou várias vezes em desistir do papel de referência, mas que conversando com os colegas continuou sendo a referência [...] após criarem uma rede de apoio interno entre os profissionais, a situação melhorou. Fala que era muito flexível e que foi aprendendo com a enfermeira $\varepsilon$. a ser mais rígida, a colocar mais limites (DPU2).

Essa rede de apoio interno entre os profissionais, que se constrói no cotidiano do trabalho, parece ser fundamental para compor um "corpo mais forte”, que ultrapassa a pessoa, criando um corpo institucional. Surge também o reconhecimento do aprendizado que se dá em equipe, em rede. No trecho a seguir, a relação/diálogo entre níveis de atenção parece possibilitar a vivência de construção de rede: Em relação ao diálogo entre UBS e especialidade, $V$. fala da importância deste e a equipe concorda. C. diz: "podemos sugerir isso, pois somos pioneiros em várias coisas" (DPU6).

As reuniões de equipe e outros encontros no território são estratégias importantes na articulação entre os profissionais e os serviços:

L. foi a uma reunião da rede e foi convidada pela gestora para conhecer a Unidade. Conheceu os profissionais e sentiu que agora tinha liberdade para ligar e estabelecer contatos. Com a UBS precisamos trabalhar mais juntos, olho no olho, isso faz as coisas fluirem melhor (DPU2).

O desafio então parece ser a criação de dispositivos flexíveis, não burocráticos, que possam construir as redes necessárias a cada situação. 
Percebe-se que isso só é possível se tomarmos a definição de rede como um conjunto de conexões que se fazem por meio de nós, sempre aberta e móvel, sendo que cada ponto desta pode estabelecer uma conexão direta com qualquer outro ponto. Essa definição contrapõe-se a um sistema organizado verticalmente e mesmo cindido em setores e departamentos, configurando a rede rizoma.

Os profissionais citam que muitas vezes são os conhecimentos pessoais que garantem o funcionamento da rede e a efetivação de processos e procedimentos previstos nas políticas:

Uma ACS teve uma familiar que iria dar a luz e nas capacitações que fez foi informada sobre o direito do pai assistir ao parto. Chegando lá, equipe da maternidade não queria autorizar, mas essa ACS disse que recebeu capacitação com uma determinada gestora e citou o nome dela, e daí eles autorizaram a entrada do pai, mas em um clima de bastante constrangimento (DPU4).

Neste caso, essa usuária, ao ter um familiar como profissional do serviço, conseguiu fazer valer um direito previsto na estrutura do sistema, mesmo assim, com dificuldade. Isso demonstra com bastante clareza como o usuário pode ficar sem poder na relação com os serviços. Dessa maneira é possível produzir saúde?

As respostas às necessidades dos usuários não são geralmente obtidas a partir de um único encontro com o sistema de saúde - ou com a atenção básica, se tomarmos a perspectiva desta como porta de entrada no sistema - tampouco com a passagem do usuário de um serviço para outro. Há necessidade de diversos encontros e contatos pontuais e também outros sequenciais que monitorem o percurso de cuidado (Mattos, 2006; Silva et al., 2011). Isso exige do profissional uma disponibilidade e qualificação para movimentar-se em rede olhando o caso ou situação de uma perspectiva ampliada. Além disso, deveria contar com o envolvimento do usuário no processo de cuidado. Mas como os profissionais veem esse envolvimento?

N. possui seus próprios modos de gerir a existência: em certa ocasião fora prescrito a ela psicotrópicos, no entanto, preferia tomar chás: "tomar chá de melissa, no fim da tarde, é bom para acalmar e relaxar, tira a ansiedade", dizia. "Já convenceu atéo médico de parar de prescrever a medicação pra ela”, ressalta com uma certa admiração a enfermeira do NAPS. Sua relação com a agente de saúde é muito próxima. São visíveis os laços de confiança e de afeto, pois há uma reciprocidade na produção do cuidado de uma com a outra (DPU2).

Em outra situação, a usuária, ao procurar a unidade em virtude de um importante emagrecimento, recebeu o diagnóstico de tuberculose, também confirmado para toda sua família. Durante o tratamento, ela engravidou e sofreu um aborto, questionado por ela como decorrente do tratamento ofertado pela unidade. Em seguida, teve o diagnóstico de infecção bacteriana resistente, o que intensificou o cuidado e o contato diário com os profissionais da atenção básica. Em todo esse processo a equipe suspeitou da existência de um transtorno alimentar, tal como bulimia, e acionou especialistas: nutricionista e psicólogo.

Nessa situação, os profissionais estavam mobilizados e buscaram construir uma rede que os ajudasse. No entanto, mesmo apesar de haver evidências diagnósticas e um longo contato com a usuária e seus familiares, há uma suspeita da equipe, denotando desconfiança naquilo que a usuária relata sobre seus sintomas. Várias são as hipóteses que podemos levantar para essa desconfiança: a tuberculose é uma doença de notificação compulsória e os usuários são monitorados intensamente, incluindo busca ativa para que não abandonem o tratamento; os transtornos alimentares, por estarem associados a transtornos mentais, sofrem discriminação. A insistência da usuária em questionar a conduta da equipe com relação ao aborto pode indicar que não estava suficientemente esclarecida, ou convencida, sobre o tratamento ao qual estava submetida. Por isso, caberá sempre perguntar nos processos de produção do cuidado: o usuário tem voz? Quanto vale sua palavra? As equipes confiam nos usuários e valorizam as informações dadas por eles?

Os movimentos da equipe no acompanhamento de um caso parecem estar sempre marcados por esse campo afetivo, no qual a conversa e a escuta garantem certo manejo, produzem certa ação. Esse 
movimento aparece também nas situações vividas pelos familiares que são responsáveis pelo cuidado. A capacidade de presença e de dar atenção a quem precisa parecem ser fundamentais nesse sentido:

"Também fiquei surpresa quando J. disse que a mãe era diabética, tinha artrose e que a principal dificuldade era se adaptar à nova vida com dificuldades de locomoção e dores, sendo que há dois anos era muito ativa e fazia tudo sozinha. J. disse que, como retorno da irmã para São Paulo, ele ficou responsável por cuidar da mãe. Em seguida disse que muitas vezes cuidar é conversar, ficar junto e dar atenção. Novamente me surpreendi". Um cuidado que sabe dos problemas e do que alivia (DPU3).

Em outra situação na qual a usuária estava com dificuldade de se deslocar sozinha para outro serviço, ao aceitar a sugestão do pesquisador de "fazer junto", a equipe parece perceber a possibilidade de uma construção conjunta de ações facilitando a atenção. Ao mesmo tempo, a equipe atribui à usuária características como "carente" e "infantil" indicando que julgamentos podem impactar os movimentos dos profissionais, bem como de investimento em projetos de cuidado.

Dizem da dificuldade dela de locomoção, e que ela manca para andar por conta da úlcera. Levantam que essa éuma limitação da rede para ela. O pesquisador pergunta: "e se agendarmos com ela e irmos juntos?", referindo-se às agendas na especialidade. A ACS responde: "acho que ela toparia. Ela é muito carente". Diz ainda que parece que ela está sempre brincando. $\varepsilon$ infantil (DPU7).

Em outro trecho vemos novamente que o usuário é visto como alguém que precisa ser tutelado, cercado, submetido ao sistema de saúde.

Alguém fala de um questionário que as gestantes devem responder e que as ACS devem aplicar semanalmente, e para isso precisam visitar as gestantes. Trata-se de um instrumento que a gestão municipal criou para poder monitorá-las de perto e que vem incomodando as ACS "mas isso de ir semanalmente aplicar um questionário acaba atra- palhando o próprio vínculo. Tem gestante que está em casa e não atende a campainha, fingindo não estar. O questionário semanal tem mais afastado a gestante do serviço do que aproximado" (DPU4).

Outro tema prevalente foi o lugar do ACS e seu papel na construção do cuidado em rede que tem fronteiras tênues em relação ao seu trabalho como profissional e a proximidade "como se fosse da família”. Em muitas de nossas reuniões com ACS, escutamos algo como "a pessoa não tem uma família, me sinto como se fosse filha, ou parente" (DPU9): "Conforme vão sendo expressos nomes, as ACS vão se conectando e compartilhando várias informações" (DPU9). Aqui podemos dizer que as ACS fazem um elo entre redes formais e informais. São profissionais dos serviços, mas também amigas, familiares e vizinhas dos usuários, detendo informações e realizando ações que articulam o público e o privado, o pessoal e o profissional.

A porosidade entre espaço/tempo de trabalho e não trabalho, entre o público e o privado, cada vez maior, de certa forma, reverteu a tendência à separação que se instalou mais fortemente a partir da Revolução Industrial, trazendo tanto a sensação de invasão quanto de organicidade, de não separação entre as diversas atividades às quais nos dedicamos.

Independente do questionário, se elas passam mal em geral nos chamam pelo Facebook ou pelo celular. A gente sabe que não pode usar esses recursos, mas elas têm nossos contatos. Nesse caso eu não me sinto incomodada em ser chamada, pois esse vínculo é legal (DPU4).

A complexidade das situações de vida e de cuidado e os afetos que emergem desses encontros aparecem como fator importante que interferem nas redes. É interessante notar que alguns profissionais consideram que o tipo de proximidade necessária à sua atuação ultrapassa aquilo que eles chamam de técnica, sendo, com frequência, situada no registro da "humanização". Na oficina realizada com as equipes para apresentar os resultados da pesquisa, uma ACS afirmou: "Há necessidades que ultrapassam sua capacidade de intervenção, aí acontece a humanização como olhar, além do olhar técnico" (DPU3). 
A experiência do cuidado depende de uma relação a ser construída e talvez seja esta medida que os profissionais estejam tateando o tempo inteiro.

\section{Considerações finais}

Ao analisarmos a produção de redes buscamos trazer elementos que incidem na produção social da saúde, que se faz por meio de uma complexa rede de relações que envolve diferentes instituições, serviços, equipes e sujeitos. Sem perder de vista a posição central do usuário, foi possível perceber tanto fragilidades quanto recursos, tramas e conexões que são cotidianamente reinventados na produção do cuidado e na composição das redes.

Buscamos neste artigo selecionar, a partir do extenso material produzido, as tensões e os múltiplos acontecimentos que comportavam os chamados trajetos já instituídos resultante de diretrizes e principalmente as chamadas linhas de fuga que permitiram que outros acontecimentos não habituais pudessem ser experimentados pelos profissionais e usuários dos serviços. A escolha dos serviços de atenção básica como ponto de partida para a investigação problematizou aspectos importantes sobre as redes formais de cuidado indicando questões relativas à comunicação entre os níveis de atenção, o uso dos protocolos, os modos como os diversos profissionais atuam ao se relacionarem com os profissionais de outros serviços e com os usuários, bem como conflitos entre o que é prescrito e o que é vivido no cotidiano dos serviços, entre outros.

Os profissionais apontam dificuldades em acionar a rede formal diante das complexas condições de vida e de cuidado e também reconhecem iniciativas individuais e criação de redes de apoio interno que facilitam suas ações. A pesquisa identificou também movimentos em direção à articulação, ao trabalho colaborativo e à criatividade diante desses desafios. As equipes foram receptivas ao tema das redes, indicando que esse termo, apesar de seus vários sentidos e de poder ser concretizado de inúmeras maneiras, não lhes é estranho. Há de se destacar que as diferentes redes se interconectam e se relacionam. As redes formais coexistem com as informais, algumas vezes não reconhecidas pelos profissionais, apontando a necessidade de se valorizar o usuário e suas redes como protagonistas na busca de apoio que nem sempre tem início nos serviços de atenção básica.

Consideramos que, embora a pesquisa tenha descrito certos desenhos estruturados, no que pudemos delinear, existe um devir-rizoma que afirma um estado criador, inventivo que tenciona a ideia de um ordenamento, um único modo de proceder/fazer cuidado tal como postulado, sem esquecer que ao mesmo tempo há uma necessidade de balizadores/ estruturas que possam facilitar os encontros e os encaminhamentos efetivos para o cuidado.

\section{Referências}

AZEVEDO, B. M. S. et al. A aposta no encontro para a produção de redes de produção de saúde. In: CONGRESSO BRASILEIRO DE POLÍTICA, PLANEJAMENTO E GESTÃO EM SAÚDE, 2., 2013, Belo Horizonte. Anais... Rio de Janeiro: Abrasco, 2013.

BRASIL. Ministério da Saúde. Secretaria de Atenção à Saúde. Implantação das Redes de Atenção à Saúde e outras estratégias da SAS. Brasília, DF, 2014.

CAMPOS, R. O. et al. Saúde mental na atenção primária à saúde: um estudo avaliativo em uma grande cidade brasileira. Ciência \& Saúde Coletiva, Rio de Janeiro, v. 16, n. 2, p. 4643-4652, 2011.

CAPRA, F. A teia da vida: uma nova compreensão científica dos sistemas vivos. São Paulo: Cultrix, 1996.

KALICHMAN, A. O.; AYRES, J. R. C. M. Integralidade e tecnologias de atenção à saúde: uma narrativa sobre contribuições conceituais à construção do princípio da integralidade no SUS. Cadernos de Saúde Pública, Rio de Janeiro, v. 32, n. 8, p. eoo183415, 2016.

KASTRUP, V. A rede: uma figura empírica da ontologia do presente. In: FONSECA, T. M. G.; KIRST, P. G. (Org.). Cartografias e devires a construção do presente. Porto Alegre: UFRGS, 2003. p. 53-62.

KASTRUP, V. O funcionamento da atenção no trabalho do cartógrafo. Psicologia \& Sociedade, Belo Horizonte, v. 19, n. 1, p. 15-22, 2007. 
KISS, L. B.; SCHRAIBER, L. B.; OLIVEIRA, A. F. P. L. Possibilidades de uma rede intersetorial de atendimento a mulheres em situação de violência. Interface: Comunicação, Saúde e Educação, Botucatu, v. 11, n. 23, p. 485-501, 2007.

MALTA, D. C. et al. Doenças crônicas não transmissíveis e o suporte das ações intersetoriais no seu enfrentamento. Ciência \& Saúde Coletiva, Rio de Janeiro, v. 19, n. 11, p. 43414350, 2014.

MATTOS R. A. Os sentidos da integralidade: algumas reflexões acerca de valores que merecem ser defendidos. In: PINHEIRO, R.; MATTOS, R. A. (Org.). Os sentidos da integralidade na atenção e no cuidado à saúde. 4. ed. Rio de Janeiro: UERJ/ IMS: Abrasco, 2006. p. 39-64.

MENDES, E. V. As redes de atenção à saúde. Brasília, DF: Organização Pan-Americana da Saúde, 2011.

MERHY, E. E. et al. Redes Vivas: multiplicidades girando as existências, sinais da rua: implicações para a produção do cuidado e a produção do conhecimento em saúde. Divulgação em Saúde para Debate, Rio de Janeiro, n. 52, p. 153-164, out. 2014.

PASSOS, E.; BARROS, R. B. A cartografia como método de pesquisa-intervenção. In: PASSOS, E.; KASTRUP, V.; ESCÓSSIA, L. (Org.). Pistas do método da cartografia: pesquisa e produção de subjetividade. Porto Alegre: Sulina, 2009. p. 17-31.

PASSOS, E.; CARVALHO, Y. M. A formação para o SUS abrindo caminhos para a produção do comum. Saúde e Sociedade, São Paulo, v. 24, p. 92101, 2015. Suplemento 1.

PEZZATO, L. M.; L'ABBATE, S. O uso de diários como ferramenta de intervenção da Análise Institucional: potencializando reflexões no cotidiano da Saúde Bucal Coletiva. Physis: Revista de Saúde Coletiva, Rio de Janeiro, v. 21, n. 4, p. 1297-1314, 2011.

PRATES, M. M. L.; GARCIA, V. G.; MORENO, D. M. F. C. Equipe de apoio e a construção coletiva do trabalho em Saúde Mental junto à Estratégia de Saúde da Família: espaço de discussão e de cuidado. Saúde e Sociedade, São Paulo, v. 22, n. 2, p. 642-652, 2013.

SERRA, C. G.; RODRIGUES, P. H. A. Avaliação da referência e contrarreferência no Programa Saúde da Família na região metropolitana do Rio de Janeiro. Ciência \& Saúde Coletiva, Rio de Janeiro, v. 15, p. 3579-3586, 2010. Suplemento 3.

SILVA, S. F. Organização de redes regionalizadas e integradas de atenção à saúde: desafios do Sistema Único de Saúde (Brasil). Ciência \& Saúde Coletiva, Rio de Janeiro, v. 16, n. 6, p. 2753-2762, 2011.

SILVA, S. F. et al. Redes de atenção à saúde no SUS: o pacto pela saúde e redes regionalizadas de ações e serviços de saúde. 2. ed. Campinas: Saberes, 2011.

TORRES, S. F. S.; BELISARIO, S. A.; MELO, E. M. A rede de urgência e emergência da macrorregião norte de Minas Gerais: um estudo de caso. Saúde e Sociedade, São Paulo, v. 24, n. 1, p. 361-373, 2015.

VANDERLEI, L. C. M.; NAVARRETE, M. L. V. Mortalidade infantil evitável e barreiras de acesso à atenção básica no Recife, Brasil. Revista de Saúde Pública, São Paulo, v. 47, n. 2, p. 379-389, 2013.

VENÂNCIO, S. I.; ROSA, T. E. C.; BERSUSA, A. A. S. Atenção integral à hipertensão arterial e diabetes mellitus: implementação da Linha de Cuidado em uma Região de Saúde do estado de São Paulo, Brasil. Physis: Revista de Saúde Coletiva, Rio de Janeiro, v. 26, n. 1, p. 113-135, 2016.

\section{Contribuição das autoras}

Todas as autoras participaram igualmente da redação deste artigo.

Recebido: $11 / 01 / 2017$

Aprovado: 18/04/2017 